\section{REVISTA CIENTÍFICA RURAL}

ISSN: $1413-8263 \quad 2525-6912$
Revista Técnico-Científica

\title{
TAMANHO DA SEMENTE E POTENCIAL FISIOLÓGICO DE TRIGO SARRACENO
}

\author{
${ }^{1 *}$ Raissa Marrafon Ponce, ${ }^{2}$ Denis Santiago Costa, ${ }^{3}$ Luiz Henrique Silva Lima, ${ }^{4}$ Helio Fernandes \\ Ibanhes Neto, ${ }^{5}$ Lúcia Sadayo Assari Takahashi \\ ${ }^{1}$ Eng. Agrônoma, Ma. em Agronomia, Universidade Estadual de Londrina, Londrina - PR; ${ }^{2}$ Eng. Agrônomo, Dr. em Fitotecnia, \\ Instituto Federal de Educação,Ciência e Tecnologia de Mato Grosso do Sul, Nova Andradina - MS; ${ }^{3}$ Eng. Agrônomo, Me. \\ em Genética e Melhoramento, Universidade Estadual de Maringá, Maringá - PR; ${ }^{4}$ Eng. Agrônomo, Me. em Agronomia, \\ Universidade Estadual de Londrina, Londrina - PR; ${ }^{5}$ Eng. Agrônoma, Dra. em Agronomia, Universidade Estadual de Londrina, \\ Londrina - PR; ( ${ }^{*}$ E-mail: raissamp@hotmail.com)
}

RESUMO: O tamanho das sementes pode ser um indicativo do potencial fisiológico da mesma, apresentando uma relação direta com a germinação e vigor, entretanto, existe divergência nos resultados encontrados em relação à espécie e cultivar. Portanto, o objetivo do trabalho foi avaliar o potencial fisiológico de duas cultivares de trigo sarraceno (IPR 91-Baili e IPR 92-Altar), em função do tamanho da semente. Inicialmente foi realizada uma caracterização das cultivares, quanto à porcentagem de sementes retidas em peneiras de 3,5; 4,0; 4,5; 5,0 e $5,5 \mathrm{~mm}$ e em seguida, a construção de um histograma para tomada de decisão sobre quais peneiras utilizar. Após a seleção, as sementes pertencentes ao lote original e as classificadas em peneiras de 3,5; 4,0; 4,5 e 5,0 mm foram submetidas a avaliações de germinação, e vigor (índice de velocidade de germinação, comprimento e massa seca de parte aérea e raiz). Constatou-se que o tamanho da semente influenciou a porcentagem de germinação e o vigor das mesmas. A germinação e o vigor das sementes foram maiores quando provenientes da peneira de tamanho 5,0 $\mathrm{mm}$. A cultivar IPR 91-Baili apresentou melhor desempenho, ao produzir plântulas com maior comprimento de raiz em relação a cultivar IPR 92-Altar.

Palavras-chave: Fagopyrum esculentum, germinação, polygonaceae, vigor

\section{SEED SIZE AND PHYSIOLOGICAL POTENTIAL OF BUCKWHEAT}

ABSTRACT: The size of the seeds may be indicative of the physiological potential of the seed, presenting a direct relation with the germination and vigor, however, there is a divergence in the results found in relation to the species and cultivar. Therefore, the objective of this work is to evaluate the physiological potential of two cultivars of buckwheat (IPR 91-Baili and IPR 92-Altar), as a function of seed size. Initially a characterization of the cultivars was carried out, regarding the percentage of seeds retained in sieves of 3.5; 4.0; 4.5; 5.0 and $5.5 \mathrm{~mm}$ and after that, made a histogram construction for the decision making of sieve breaks. After selection, the seeds 
belonging to the original lot and those classified in sieves of 3.5; 4.0; 4.5 and $5.0 \mathrm{~mm}$ the seeds were submitted to germination and vigor evaluations (germination speed index, length and dry mass of shoots and roots). It was verified that the size of the seed influenced the percentage of germination and vigor. The germination and vigor seed was higher in those coming from the $5.0 \mathrm{~mm}$ size sieve. The cultivar IPR 91Baili presented better performance, when producing seedlings with greater root length in relation to cultivating IPR 92-Altar.

Keywords: Fagopyrum esculentum, germination, polygonaceae, vigor

\section{INTRODUÇÃO}

A espécie Fagopyrum esculentum Moench pertencente à família Polygonaceae, é conhecido popularmente como trigo mourisco, mouro, preto ou sarraceno. Seus grãos são uma alternativa na alimentação humana, principalmente para pessoas com doença celíaca, devido à ausência do glúten em sua composição, além do potencial uso como adubo verde e alimento animal (GONÇALVES et al., 2016; GUO et al., 2007; FESSAS et al., 2008).

Por se tratar de uma planta multiplicada por meio de sementes, é fundamental que na implantação dessa cultura, cuidados sejam tomados como utilização de genótipos superiores, germinação e vigor elevado a fim de, garantir o estabelecimento das plantas em campo.

A germinação da semente é a característica fisiológica que indica o potencial de reproduzir uma nova planta, e é condicionada pelo desenvolvimento regular do embrião e pela quantidade de reservas disponíveis, sendo esses, pré-requisitos necessários para o desenvolvimento de uma plântula vigorosa e uma planta bem desenvolvida (ADEBISI et al., 2013). Por outro lado, o vigor é a soma de atributos que determinam o potencial das sementes germinarem rápido e uniformemente sob condições adversas de ambiente (BAALBAKI et al., 2009). Quando estudados juntos, germinação e vigor, se expressa o potencial fisiológico das sementes (MARCOS FILHO, 2015).

Dentre as características físicas das sementes que afetam o desempenho das plântulas, o tamanho é um dos componentes a influenciar o estabelecimento da cultura (AMBIKA et al., 2014), sendo seu efeito atribuído ao fato de sementes maiores possuírem elevada quantidade de reservas, o que pode explicar o aumento no crescimento de plântulas e no vigor (FINCH-SAVAGE; BASSEL, 2016). 
Trabalhos têm sido conduzidos afim de, associar as características de tamanho, com o seu desempenho em testes de laboratório e em condições de campo (ZUCARELI et al., 2014). Para diversas espécies, é notado que os diferentes tamanhos da semente influenciam em características de germinação, de vigor e de produção. Para a cultura do tamarindo (Tamarindus indica), sementes grandes e muito grandes, produzem plantas de maior diâmetro de coleto, maior massa seca de parte aérea e raiz, portanto, a classificação das sementes é uma técnica que deve ser recomendada (Pereira et al., 2008). Também, em soja (Glycine max), de acordo com Pádua et al. (2010), maiores porcentagens de germinação e vigor são observadas em sementes com maiores tamanhos.

Para a cultura do trigo sarraceno, o efeito do tamanho das sementes sobre a germinação e vigor não tem sido abordado pela literatura, sendo necessários estudos sobre essa temática para a espécie. Portanto, objetivou-se avaliar o potencial fisiológico das sementes de duas cultivares de trigo sarraceno, em função do tamanho da semente.

\section{MATERIAL E MÉTODOS}

Sementes comerciais de trigo sarraceno, representadas por dois cultivares (IPR 91-Baili e IPR 92-Altar), foram fornecidas pelo Instituto Agronômico do Paraná (IAPAR), Londrina-PR e mantidas sob temperatura constante de $10^{\circ} \mathrm{C}$ até $\mathrm{O}$ momento da montagem do experimento.

A fim de obter classes de tamanho, as sementes foram homogeneizadas e, quatro repetições de 200 gramas classificadas em peneiras de crivo circular, dispostas em ordem decrescente (5,5; 5,0; 4,5; 4,0 e 3,5 mm), sob agitação de um minuto. As sementes retidas em cada classe foram pesadas em balança digital com precisão de 0,001 g, e em seguida, calculado o percentual de retenção por peneira. Com os dados obtidos, realizou-se a construção de um histograma para tomada de decisão sobre quais peneiras se utilizar.

A partir desse resultado preliminar instalou-se um experimento sob delineamento inteiramente ao acaso, em esquema fatorial $2 \times 5$, constituído pela combinação entre cultivar (IPR 91-Baili e IPR 92-Altar) e tamanho de sementes (sementes retidas em peneiras de 5,$0 ; 4,5 ; 4,0 ; 3,5 \mathrm{~mm}$ e lote original, sem 
classificação em peneira), com quatro repetições. O potencial fisiológico das sementes de trigo sarraceno foi avaliado de acordo com os seguintes testes:

Germinação: 50 sementes foram dispostas sobre duas folhas de papel toalha, e coberta por uma terceira folha, umedecidas com água destilada na proporção de 2,5 vezes a massa do papel seco. Em seguida, confeccionou-se rolos de papel, que foram mantidos em germinador do tipo Mangelsdorf, à temperatura de $25^{\circ} \mathrm{C}$, e efetuada a contagem de plântulas, no sétimo dia. Os critérios utilizados para a classificação de plântulas normais, anormais, sementes mortas e dormentes seguiram as recomendações propostas pelas Regras para Análise de Sementes (BRASIL, 2009).

Índice de velocidade de germinação: foi conduzido em conjunto com a germinação, e a partir dos dados registrados diariamente do número de plântulas com emissão de raiz primária, foi calculada a velocidade de germinação, empregando-se a fórmula sugerida por (MAGUIRE, 1962).

Comprimento de parte aérea e raiz: ao final do teste de germinação, 10 plântulas normais obtidas, tiveram seus comprimentos mensurados, por meio de régua milimétrica, e os resultados expressos em $\mathrm{cm} /$ plântula, adaptado de Nakagawa (1999), para forma de obtenção e número de plântulas.

Massa seca de parte aérea e raiz: ao final do teste de germinação, 10 plântulas normais foram separadas em parte aérea e raiz, e obtida a massa seca a partir de pesagens em balança analítica de precisão $(0,001 \mathrm{~g})$, dos materiais que ficaram em estufa regulada à $80^{\circ} \mathrm{C}$ por 24 horas, estes resultados foram expressos em mg/plântula (adaptado de NAKAGAWA, 1999).

Os resultados foram submetidos à análise de variância pelo teste $F$, e as médias dos tratamentos comparadas pelo teste de Duncan a $5 \%$ de significância, utilizando-se o software estatístico R.

\section{RESULTADOS}

A partir do histograma obtido após a classificação das sementes (Figura 1), observou-se que os dados apresentaram comportamento similar a uma distribuição normal, com os extremos das peneiras (3,5 e 5,5 mm) apresentando menores porcentagens de retenção de sementes em ambas as cultivares. Verificou-se Revista Científica Rural, Bagé-RS, volume21, nำ2, ano 2019 Submetido 23/07/2018. Aceito 25/09/2018. Doi: https://doi.org/10.30945/rcr-v21i2.354 
também, que as maiores quantidades de sementes estavam retidas nas peneiras 4,5; 4,0 e 5,0 mm respectivamente. Em função da pequena disponibilidade de sementes retida na peneira de $5,5 \mathrm{~mm}$, esta não foi utilizada nas avaliações seguintes.

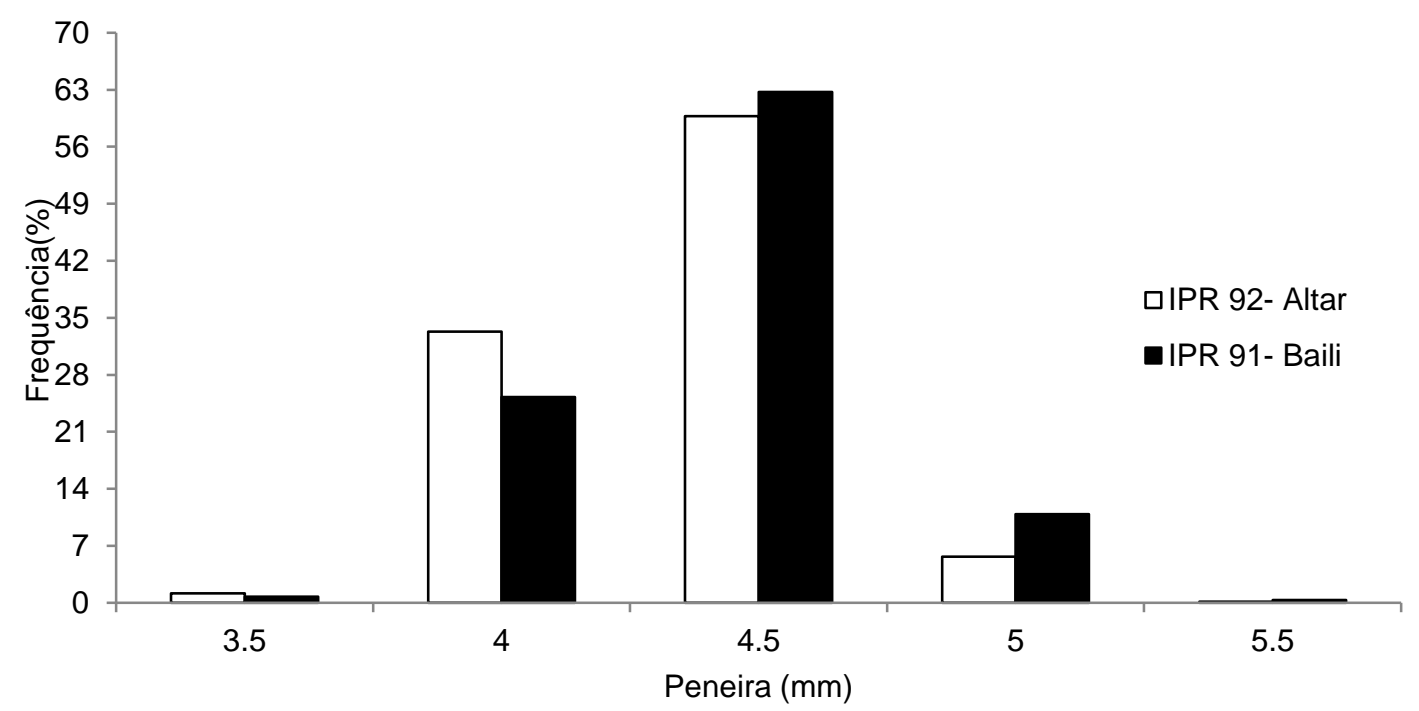

Figura 1. Retenção de sementes de duas cultivares de trigo sarraceno, em diferentes peneiras. Figure 1. Retention of seeds of buckwheat cultivars in different sieves.

De acordo com os dados da análise de variância (Tabela 1), para as diferentes peneiras, constatou-se nas avaliações de germinação, índice de velocidade de germinação e massa seca de parte aérea e raiz, efeito significativo a $5 \%$ de probabilidade. Semelhantemente, constatou-se efeito significativo entre as cultivares, apenas para o comprimento de raiz.

Tabela 1. Resumo da análise de variância da germinação $(G)$, índice de velocidade de germinação (IVG), comprimento de parte aérea (CPA) e raiz (CR), massa seca de parte aérea (MSPA) e raiz (MSR), oriundas de cinco peneiras e duas cultivares.

Table 1. Summary of variance analysis of germination (G), germination speed index (GSI), shoot length (SL) and root (SR), shoot dry mass (SDM) and root (SDR) sieves and two cultivars.

\begin{tabular}{|c|c|c|c|c|c|c|c|}
\hline \multirow{2}{*}{ Fonte de variação } & \multirow{2}{*}{ GL } & \multicolumn{6}{|c|}{ Quadrados médios } \\
\hline & & $\mathrm{G}$ & IVG & CPA & CR & MSPA & MSR \\
\hline Cultivar & 1 & $0,1^{\mathrm{ns}}$ & $7,7^{\text {ns }}$ & $0,0009^{n s}$ & $0,1291^{*}$ & $1,3 \times 10^{-5} \mathrm{~ns}$ & $1,3 \times 10^{-5} \mathrm{~ns}$ \\
\hline Peneira & 4 & $17,4^{*}$ & $75,2^{*}$ & $0,0054^{\text {ns }}$ & $0,0299^{\text {ns }}$ & $9 \times 10^{-4}$ * & $6,3 \times 10^{-5}$ * \\
\hline Cultivar x Peneira & 4 & $4,6^{\text {ns }}$ & $2,4^{\mathrm{ns}}$ & $0,0064^{\text {ns }}$ & $0,0534^{\mathrm{ns}}$ & $3,6 \times 10^{-5} \mathrm{~ns}$ & $2,7 \times 10^{-5} \mathrm{~ns}$ \\
\hline Resíduo & 30 & 6,4 & 2,3 & 0,0091 & 0,0254 & $3 \times 10^{-5}$ & $6,8 \times 10^{-5}$ \\
\hline CV (\%) & & 2,58 & 3,55 & 9,72 & 12,82 & 6,2 & 8,86 \\
\hline
\end{tabular}

ns, ${ }^{*}$, não significativo e significativo a $5 \%$ de probabilidade pelo teste $\mathrm{F}$, respectivamente;

CV- Coeficiente de variação. 
$\mathrm{Na}$ Tabela 2, encontram-se os valores médios do teste de germinação, onde constatou-se que as sementes retidas na peneira de 3,5 mm apresentaram menor porcentual de germinação, diferindo-se daquelas provenientes das peneiras de 4,5 e $5,0 \mathrm{~mm}$ e do lote original. Para o índice de velocidade de germinação (Tabela 2), as sementes oriundas de peneiras de 3,5 e 4,0 mm germinaram mais rapidamente.

Para a massa seca de parte aérea (Tabela 2) as sementes retidas na peneira de 5,0 mm resultou em maior valor médio. Da mesma forma, as peneiras 4,5; 4,0 $\mathrm{mm}$ e lote original apresentaram resultados superiores de massa seca, em relação às sementes de peneira $3,5 \mathrm{~mm}$. Semelhantemente, os resultados de massa seca de raiz (Tabela 2), nas peneiras de maior tamanho $(5,0 ; 4,5 \mathrm{~mm}$ e lote original), diferiram-se da peneira de 3,5 mm. Quanto as cultivares foi observado diferenças no comportamento de crescimento da raiz (Tabela 2). O valor médio do comprimento de raiz para a cultivar IPR 91-Baili, foi superior ao IPR 92-Altar.

Tabela 2. Germinação (G), índice de velocidade de germinação (IVG), massa seca de parte aérea (MSPA) e raiz (MSR) em função da peneira, e comprimento de raiz (CR) em função da cultivar.

Table 2. Germination (G), germination speed index (GSI), shoot dry mass (SDM) and root (SDR) as a function of the sieve, and root length $(\mathrm{RL})$ as a function of the cultivar.

\begin{tabular}{|c|c|c|c|c|}
\hline \multirow{2}{*}{ Peneira (mm) } & \multirow{2}{*}{$\mathrm{G}(\%)$} & \multirow{2}{*}{ IVG } & \multirow{2}{*}{\multicolumn{2}{|c|}{$\frac{P A}{\text { (mg/plântula) }}$}} \\
\hline & & & & \\
\hline 3,5 & $95 \mathrm{~b}$ & $45,18 \mathrm{a}$ & $74 \mathrm{~d}$ & $26 \mathrm{~d}$ \\
\hline 4,0 & $97 a b$ & 44,93 a & $87 \mathrm{c}$ & $27 \mathrm{~cd}$ \\
\hline 4,5 & $99 a$ & $41,88 \mathrm{~b}$ & $92 \mathrm{~b}$ & $32 a b$ \\
\hline 5,0 & $98 \mathrm{a}$ & $37,58 \mathrm{c}$ & $103 a$ & $33 \mathrm{a}$ \\
\hline Lote original & $99 \mathrm{a}$ & $42,48 \mathrm{~b}$ & $85 c$ & $30 \mathrm{bc}$ \\
\hline \multirow{2}{*}{ Cultivar } & \multicolumn{4}{|c|}{ CR } \\
\hline & \multicolumn{4}{|c|}{ (cm/plântula) } \\
\hline IPR 91 Baili & \multicolumn{4}{|c|}{$13,0 \mathrm{a}$} \\
\hline IPR 92 Altar & \multicolumn{4}{|c|}{$11,9 \mathrm{~b}$} \\
\hline
\end{tabular}

Médias seguidas pela mesma letra minúscula na coluna, não diferem entre si pelo teste de Duncan a 5\% de probabilidade.

\section{DISCUSSÃO}

O comportamento similar à distribuição normal em semente é comum de se observar na natureza, em função de características intraespecíficas de distribuição do florescimento ao longo do ciclo, posição da semente na planta e o tempo para maturação. Em outras espécies resultados similares foram observados, como em sementes de faveira (Clitoria fairchildiana) na qual se verificou maior porcentagem 
de sementes para as de tamanho intermediário (SILVA E CARVALHO, 2008), bem como, em sementes de carnaúba hospedeira (Copernicia hospita), cuja maior frequência de distribuição, concentrou-se nos diâmetros intermediários, em relação às extremidades (OLIVEIRA; BOSCO, 2013).

$\mathrm{Em}$ algumas espécies como a soja (Glycine max) e mamona (Ricinus communis), o tamanho da semente influencia o sucesso da germinação (PÁDUA et al., 2010; ZUCHI et al., 2010). Para o trigo sarraceno as sementes menores podem estar imaturas, e com menores quantidades de reserva, consequentemente, não dão suporte suficiente para a germinação.

Sementes menores de açafrão-bastardo (Carthamus tinctorius) apresentaram maior índice de velocidade de germinação, em relação aquelas de tamanho maior (SADEGHI et al., 2011). Tal fato é justificado pelas sementes menores apresentarem maior área de contato com a água, o que implica, em um inicio do processo de germinação mais rápido, quando comparado àquelas com menor área de contato (ARAUJO et al., 2014).

A massa seca da parte aérea proveniente de sementes retidas em peneira de 5,0 mm apresentou maior valor médio. Da mesma forma, as peneiras 4,5; 4,0 $\mathrm{mm}$ e lote original apresentaram resultados superiores de massa seca, em relação às sementes de peneira 3,5 $\mathrm{mm}$. A presença de embriões bem formados, com maior tamanho e maior conteúdo de tecido de reserva, origina componentes estruturais mais pesados, na formação da plântula. Em ambas as cultivares de trigo sarraceno, as sementes maiores proporcionaram melhor desempenho de plântulas. Em sementes de sansão-do-campo (Mimosa caesalpiniifolia), os maiores tamanhos de semente proporcionaram maior massa seca de raiz (ALVES et al., 2005).

Quanto as cultivares foi observado diferenças no comportamento de crescimento da raiz (Tabela 2). O valor médio do comprimento de raiz para a cultivar IPR 91-Baili, foi superior ao IPR 92-Altar. A diferença observada no comportamento de crescimento da raiz entre as cultivares, deve atribuída, a diferença genética entre as cultivares, uma vez que não houve interferência do tamanho de sementes. Para aquela com maior desenvolvimento, é possível que as raízes cresçam e respondam melhor as adversidades ambientais, proporcionando melhor suporte para o desenvolvimento e sobrevivência da planta. 


\section{CONCLUSÕES}

O tamanho da semente influencia a porcentagem de germinação e o vigor de sementes de trigo sarraceno. Sementes maiores resultam em maior porcentagem de germinação e maior acúmulo de matéria seca, independente da cultivar.

A cultivar IPR 91-Baili produz plântulas com maior comprimento de raiz em relação à IPR 92-Altar.

\section{AGRADECIMENTOS}

Ao Instituto Agronômico do Paraná (IAPAR) por disponibilizar as sementes e a Coordenação de Aperfeiçoamento de Pessoal de Nível Superior (CAPES) pelo apoio financeiro aos estudos e pesquisas científicas.

\section{REFERÊNCIAS}

ADEBISI, M. A.; KEHINDE, T. O.; SALAU, A. W.; OKESOLA, L. A.; PORBENI, J. B. O.; ESURUOSO, A. O.; OYEKALE, K. O. Influence of different seed size fractions on seed germination, seedling emergence and seed yield characters in tropical soybean (Glycine max L. Merrill). International Journal of Agricultural Research, v.8, n.1, p.2633, 2013. DOI: http://dx.doi.org/10.3923/ijar.2013.26.33

ALVES, E. U.; BRUNO, R. L. A.; OlIVEIRA, A. P.; ALVES, A. U.; ALVES, A. U.; PAULA, R. C. Influência do tamanho e da procedência de sementes de Mimosa caesalpiniifolia Benth. sobre a germinação e vigor. Revista Árvore, v. 29, n.6, p.877885, 2005. DOI: http://dx.doi.org/10.1590/S0100-67622005000600006.

AMBIKA, S.; MANONMANI, V.; SOMASUNDAR, G. Review on effect of seed size on seedling vigour and seed yield. Research Journal of Seed Science, v.7, n.2, p.31-38, 2014. DOI: http://dx.doi.org/10.3923/rjss.2014.31.38

ARAUJO, R. F.; ZONTA, J. B.; ARAÚJO, E. F.; DONZELES, S. M. L.; COSTA, G. M. Curva de absorção de água em sementes de pinhão-manso (Jatropha curcas L.). Idesia (Chile), v.32, n.2, p.5-10, 2014. DOI: http://dx.doi.org/10.4067/S071834292014000200002 
BAALBAKI, R.; ELIAS, S.; MARCOS FILHO, J.; MCDONALD, M. B. Seed vigor testing handbook. AOSA, NY, USA. (Contribution to the Handbook on Seed Testing, 32). 2009.

BRASIL. Regras para análise de sementes. Brasília: Ministério da Agricultura, Pecuária e Abastecimento, 2009, 399p.

FESSAS, D.; SIGNORELLI, M.; PAGANI, A.; MARIOTTI, M.; IAMETTI, S.; SCHIRALDI, A. Guidelines for buckwheat enriched bread thermal analysis approach. Journal of Thermal Analysis and Calorimetry, v.91, n.1, p.9-16, 2008. DOI: https://doi.org/10.1007/s10973-007-8594-6

FINCH-SAVAGE, W. E.; BASSEL, G. W. Seed vigour and crop establishment: Extending performance beyond adaptation. Journal of Experimental Botany, v.67, n.3, p.567-591, 2016. DOI: https://doi.org/10.1093/jxb/erv490

GONÇALVES, F. M. F.; DEBIAGE, R.; SILVA, R. M. G.; PORTO, P. P.; YOSHIHARA, E.; PEIXOTO, E. C. T. M. Fagopyrum esculentum Moench: A crop with many purposes in agriculture and human nutrition. African Journal of Agricultural Research, v.11, n.12, p. 983-989, 2016. DOI: https://doi.org/10.5897/AJAR2015.10747

GUO, Y. -Z.; CHEN, Q. -F.; YANG, L. -Y.; HUANG, Y. -H. Analyses of the seed protein contents on the cultivated and wild buckwheat Fagopyrum esculentum resources. Genetic Resources and Crop Evolution, v.54, n.7, p.1465-1472, 2007. DOI: https://doi.org/10.1007/s10722-006-9135-z

MAGUIRE, J. D. Speed of germination- aid in selection and evaluation for seedling emergence and vigor. Crop Science, v.2, n.2, p. 176-177, 1962.

MARCOS FILHO, J. Seed vigor testing: an overview of the past, present and future perspective. Scientia Agricola, v.72, n.4, p.363-37, 2015. DOI: http://dx.doi.org/10.1590/0103-9016-2015-0007

NAKAGAWA, J. Testes de vigor baseados no desempenho das plântulas. In: Krzyzanowski, F.C., Vieira, R.D., França Neto, J.B. Vigor de sementes: Conceitos e testes. Londrina: ABRATES, 1999. p. 1-24. 
OLIVEIRA, A. B.; BOSCO, M. R. O. Biometria, determinação da curva de absorção de água em sementes e emergência inicial de plântulas de Copernicia hospita Martius. Revista Brasileira de Agroecologia, v.8, n.1, p.66-74, 2013.

PÁDUA, G. P.; ZITO, R. K.; ARANTES, N. E.; FRANÇA NETO, J. B. Influência do tamanho da semente na qualidade fisiológica e na produtividade da cultura da soja. Revista Brasileira de Sementes, v.32, n.3, p.9-16, 2010. DOI: http://dx.doi.org/10.1590/S0101-31222010000300001

PEREIRA, P. C.; FReITAS, R. S.; MELO, B.; AlMeidA, A.; PEREIRA, A. P.; SANTANA, G.; MAGNO, J.; LUZ, Q. Influência do tamanho de sementes na qualidade de mudas de tamarindeiro. Bioscience Journal, v.24, n.4, p.73-79, 2008.

SADEGHI, H.; KHAZAEI, F.; SHEIDAEI, S.; YARI, L. Effect of seed size on seed germination behavior of safflower (Carthamus tinctorius L.). Journal of Agricultural and Biological Science, v.6, n.4. p.5-8, 2011.

SILVA, B. M. S.; CARVALHO, N. M. Efeitos do estresse hídrico sobre o desempenho germinativo da semente de faveira (Clitoria fairchildiana R.A. Howard.-Fabaceae) de diferentes tamanhos. Revista Brasileira de Sementes, v.30, n.1, p.55-65, 2008. DOI: http://dx.doi.org/10.1590/S0101-31222008000100008

ZUCARELI, C.; BRZEZINSKI, C. R.; GUISCEM, J. M.; HENNING, F. A.; NAKAGAWA, J. Qualidade fisiológica de sementes de milho doce classificadas pela espessura e largura. Pesquisa Agropecuaria Tropical, v.44, n.1, p.71-78, 2014. DOI: http://dx.doi.org/10.1590/S1983-40632014000100009

ZUCHI, J.; PANOZZO, L. E.; HEBERLE, E.; DIAS, D. C. F. S. Qualidade fisiológica de sementes de mamona. Revista Brasileira de Sementes, v.32, n.3, p.177-183, 2010. DOI: http://dx.doi.org/10.1590/S0101-31222010000300020 